\title{
Movement Disorders: An Update
}

Can. J. Neurol. Sci. 2003; 30: Suppl. 1 - S1

Over the past 20 years, the area of Movement Disorders has grown to become a well-defined subspecialty with large, multidisciplinary clinical services available in all Canadian cities and university centres.

This time period also saw the development of the Canadian Movement Disorders Group (CMDG) which is composed of neurologists interested in, or specializing in movement disorders. The CMDG is an active part of the Canadian Neurological Society, meeting yearly during the annual meeting of the Canadian Congress of Neurological Sciences and regularly organizing courses for the Congress.

In the early 1990s, the CMDG felt that it would be important to provide residents with comprehensive exposure to the diagnosis and treatment of movement disorders. As a result, under the leadership of Drs. Mark Guttman and Jon Stoessl, the National Residents'Course was born.

Since then, the course has occurred yearly, taught by many of the movement disorders specialists across Canada. The curriculum involves video diagnosis and case-based workshops and has consistently earned many accolades from the residents for its comprehensive nature and unbiased approach. Each faculty member has provided a manuscript on their topics, published as a handbook for the residents.

In 2001, we celebrated the 10th year anniversary of the course. In commemoration, we felt that it would be appropriate to publish the collection of articles based on the course, as a supplement in the Canadian Journal of Neurological Sciences. The articles are meant to provide a clinical approach for diagnosis and treatment of the wide range of movement disorders that are seen in clinical practice, with updates on recent advances in each area.

I would like to express my gratitude to my colleagues for providing the articles with very tight timelines, to our corporate sponsors who have provided funding support for the course over the years, and Draxis Pharmaceutica Inc. for their funding of the supplement with an unrestricted educational grant. All articles in the supplement have been peer reviewed to ensure quality and unbiased information.

Oksana Suchowersky, Supplement Editor 